\title{
The first lady president of the ISPN: Prof. Dr. Graciela Zuccaro and her journey through pediatric neurosurgery
}

\author{
Zulma Tovar-Spinoza ${ }^{1}$ (D)
}

Received: 3 May 2017 / Accepted: 5 June 2017 /Published online: 20 June 2017

(C) Springer-Verlag GmbH Germany 2017

\begin{abstract}
The International Society for Pediatric Neurosurgery (ISPN) was founded in 1972 in Chicago, IL, USA. It has been 45 years since the creation of the ISPN, but it is not until now that the pediatric neurosurgery community has been led by a female neurosurgeon.
\end{abstract}

Keywords Pediatric neurosurgery $\cdot$ ISPN $\cdot$ CLANPED

\section{Introduction}

The International Society for Pediatric Neurosurgery (ISPN) was founded in 1972 in Chicago, IL, USA. The ISPN seeks to promote the health of children throughout the world by encouraging the ethical transmission and exchange of neuroscientific information and techniques related to pediatric neurosurgery [1].

It has been 45 years since the creation of the ISPN, but it is not until now that the pediatric neurosurgery community has been led by a female neurosurgeon.

\section{Background}

Graciela Noemi Zuccaro grew up in la Ciudad de la Plata, Buenos Aires, Argentina. Her mother, Irma Conti de

Zulma Tovar-Spinoza

tovarspz@upstate.edu

1 Department of Neurosurgery, SUNY Upstate Medical University, 750 E Adams St, 604 Jacobsen Hall, Syracuse, NY 13210, USA
Zuccaro, owned a beauty salon, and her father, Rodolfo Zuccaro, was a government officer. She and her sister, Maria Cristina, attended the Maria Auxiliadora Catholic school where Graciela earned her degree as a teacher. Her sister became an architect while Graciela declined her acceptance as a classical ballerina to the Argentine Theater of La Plata and pursued her vocation, obtaining her degree in medicine with honors at the Universidad de la Plata on August of 1973 (Fig. 1).

\section{Pediatric neurosurgery}

In 1974, Dr. Zuccaro moved to the city of Buenos Aires and initiated her first steps in pediatric neurosurgery under the tutorial of Dr. Raul Carrea at the Children's Hospital Ricardo Gutierrez. She graduated as a pediatric neurosurgeon in 1978. Upon finishing her residency, Dr. Zuccaro did a fellowship in microsurgery in 1985 at the Henry Ford Institute in Detroit and continued her formation with base of skull surgery training at the University of Cincinnati and at the University of Virginia. She then became a fellow at the Children's Hospital of Philadelphia under the guidance of Professor Luis Schut. Later on, in 2000, she specialized in neuroendoscopy under the tutelage of Professor Fernando Rueda Franco at the National Institute of Pediatrics in Mexico City.

To broaden her scope of neurosurgery, Graciela visited and observed the prominent masters of neurosurgery at work: James Ausman, Vinko Dolenc, Anthony Raimondi, Maurice Choux, Gazy Yasargil, Majid Samii, Evandro de Oliveira, and Christian Sainte-Rose.

Dr. Zuccaro assumed her first faculty position in 1979 at the Children's Hospital "Ricardo Gutiérrez" in Buenos Aires, 
Fig. 1 Dr. Zuccaro's medical school graduation, 1973. (Top row, second from right)

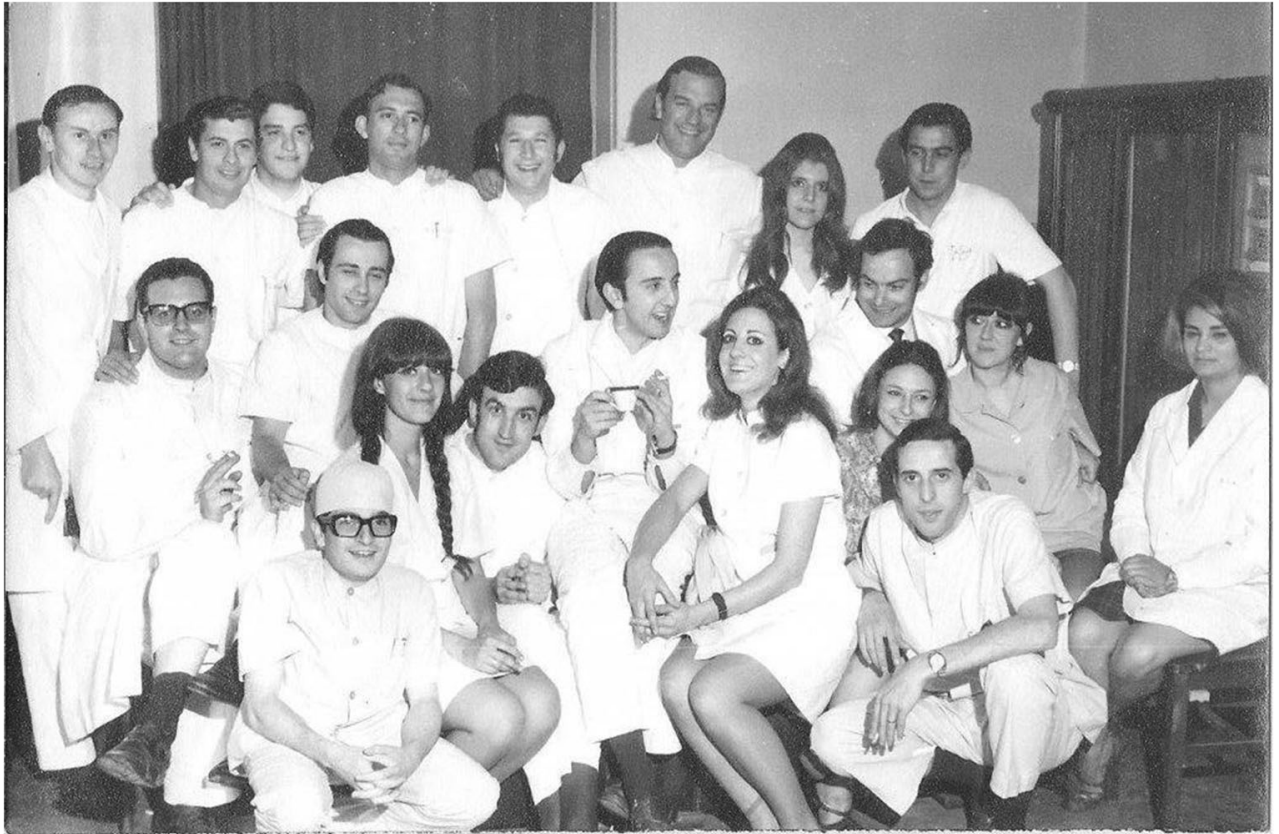

a position she maintained until 1987 when she transferred to the National Pediatric Hospital "Prof. Dr. Juan P. Garrahan" where Dr. Zuccaro was appointed Chief of neurosurgery from 2003 to 2014; simultaneously, she was a professor of pediatric neurosurgery at the Faculty of Medicine of University of Buenos Aires, where she continues to be an honorary faculty (Fig. 2).
Along with her clinical and academic trajectory (148 pages of curriculum vitae), Dr. Zuccaro has been part of the editorial board of multiple scientific publications; they include La Revista Argentina de Neurocirugia, Child's Nervous System, Journal Brasileiro de Neurocirugia, Surgical Neurology, and Journal of Hydrocephalus to mention just a few (Fig. 3).
Fig. 2 Dr. Zuccaro with her husband and children the day she was named Chief of neurosurgery at the Garrahan Hospital, 2003

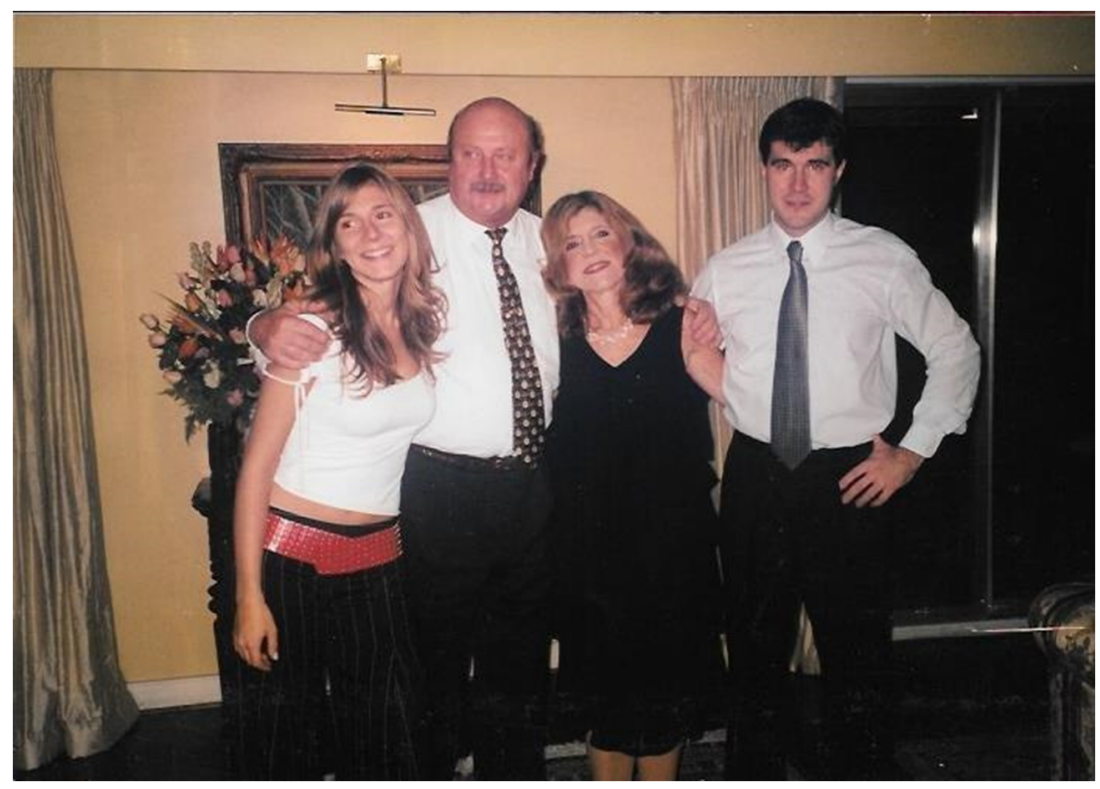


Fig. 3 Child Nervous System meeting at Prof. Raimondi's house, 1999. From superior left: Prof. G. Zuccaro, A. J. Raimondi, E. Ventureyra, C. Di Rocco, S. Matsumoto, and M. Caldarelli; from inferior left: Prof. S. Oi, A. Ammar, and Mrs. Matsumoto

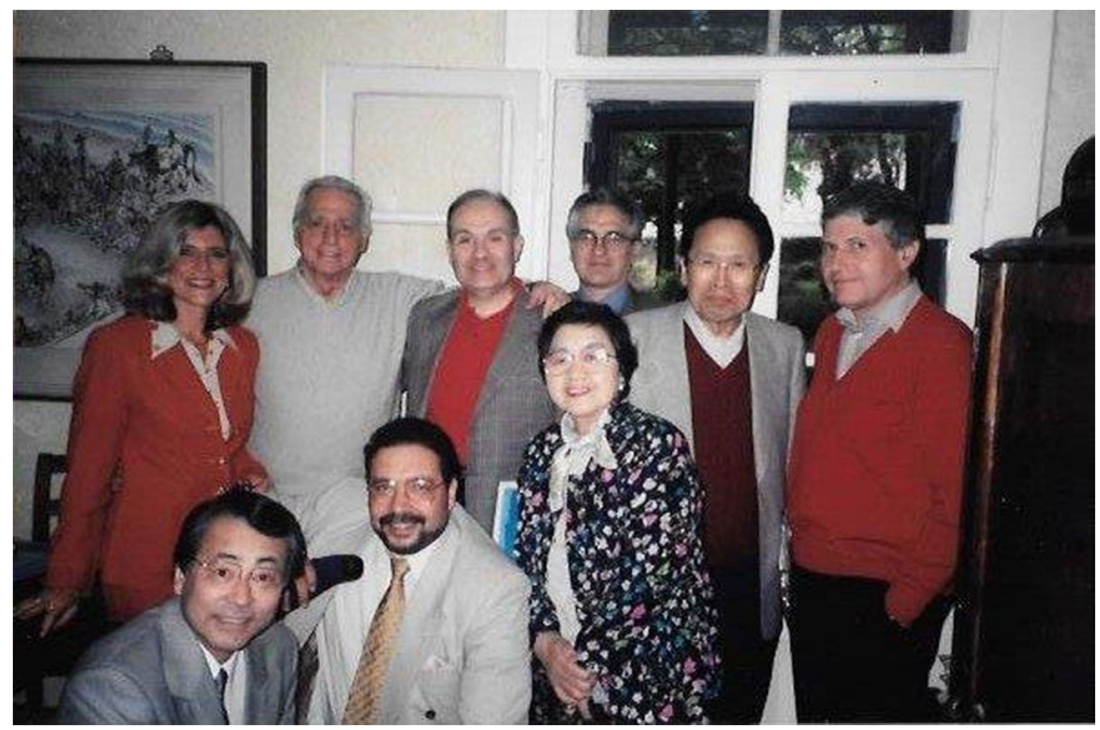

Dr. Zuccaro has participated in numerous local, national, and international neurosurgical meetings, presenting over 210 and 104 articles in national and international conferences, respectively. She has published 35 peer reviewed manuscripts and nine book chapters.

Together with some of her Latin-American colleagues, Dr. Zuccaro had the vision of expanding the links of LatinAmerican neurosurgery with the creation of programs of clinical and educational cooperation with the neurosurgeons worldwide. With this in mind, the pediatric neurosurgery chapter of the Latin-American Neurosurgical Federation (CLANPED) was founded in Cordoba, Argentina, in 2001 with the presence of Maurice Chox, Harold Rekate, Francisco Rueda Franco, Christian Sainte-Rose, Concezio Di Rocco, Sergio Valenzuela, and then the president of the Argentinian Neurosurgical Society Julio Cesar Suarez
Fig. 4 Creation of the LatinAmerican Chapter of Pediatric Neurosurgery (CLANPED); Cordoba, Argentina, 2001. From left to right: Roberto Jaimovich (Argentina), Julio Cesar Suarez (Argentina), Christian Sainte Rose (France), Graciela Zuccaro (Argentina), Fernando Rueda Franco (Mexico), Guillermo Ajler (Argentina), Maurice Choux (France), Concezio Di Rocco (Italy), Sergio Valenzuela (Chile), Arturo Zuleta (Chile), and Harold Rekate (USA)

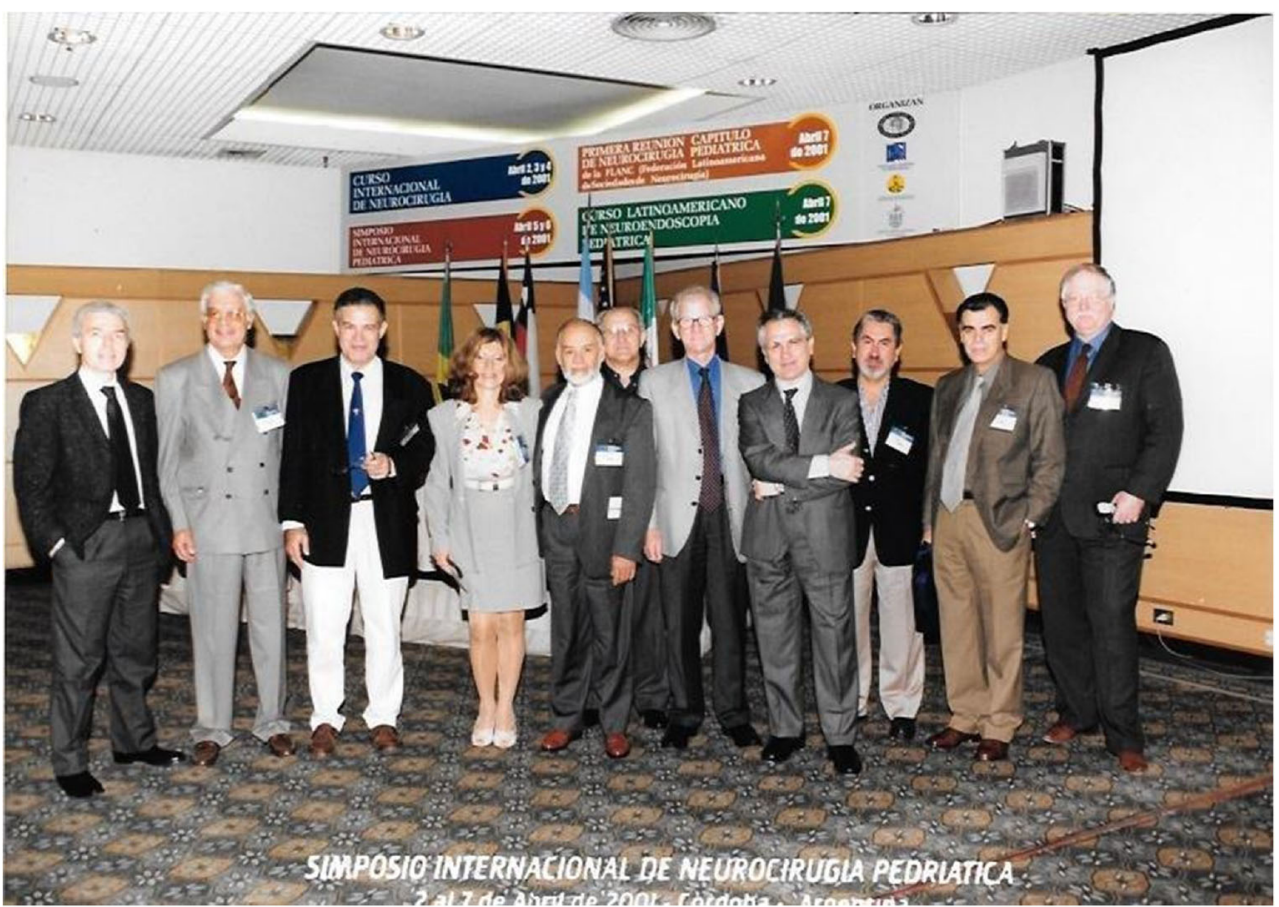


Fig. 5 Third International Course of Pediatric Neurosurgery of the Neurosurgical Latin-American Federation

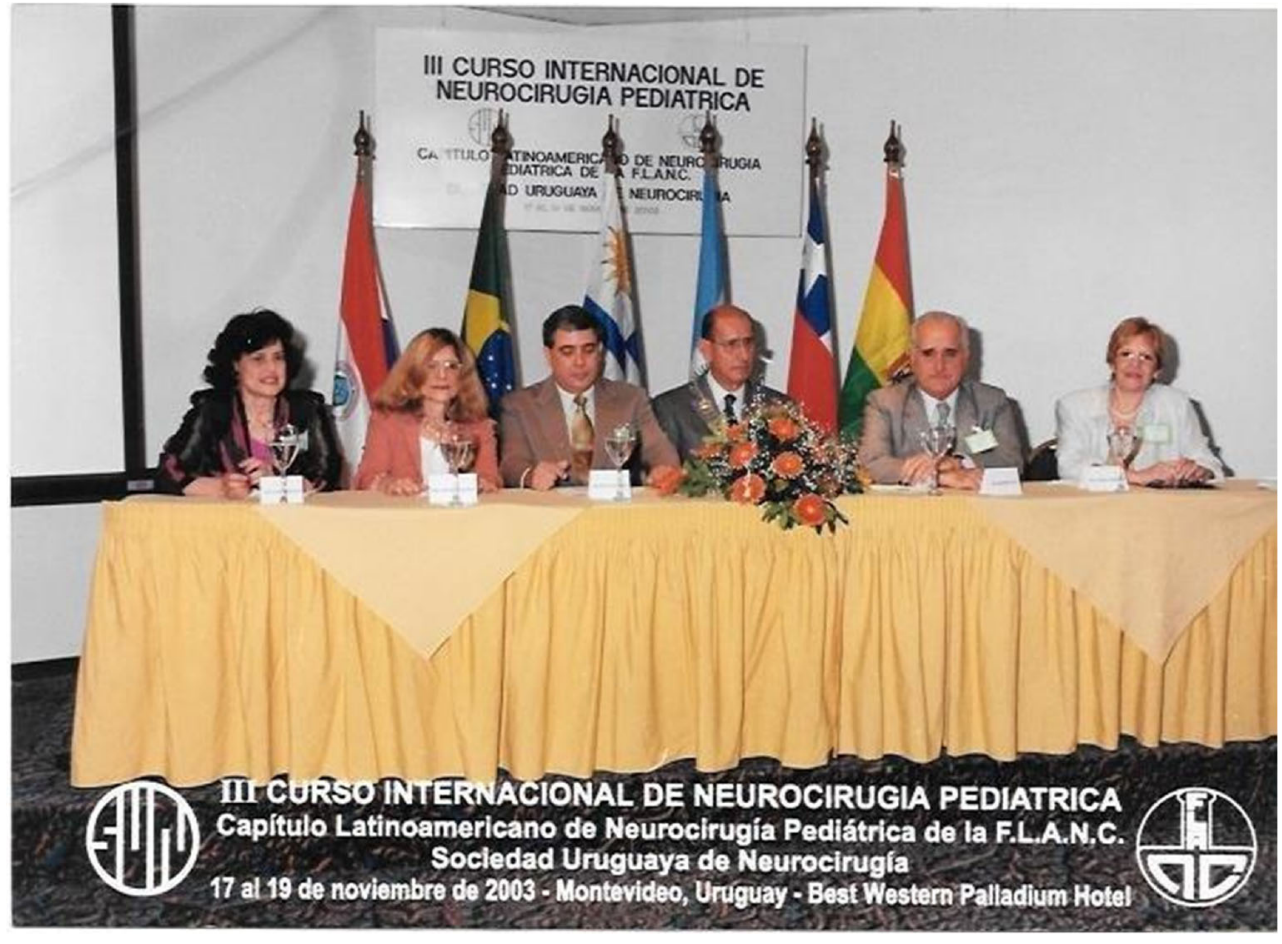

(Fig. 4). Dr. Zuccaro served as president of the CLANPED from 2006 to 2008 [2].

Dr. Zuccaro is highly regarded by her Latin-American colleagues who bestowed her with numerous honors. To mention some, she is an honorary member of the Chilean Society of Neurosurgery (2002), honorary member of the Bolivian Society of Neurosurgery (2004), honorary member of the Venezuelan Society of Neurosurgery (2006),
Neurosurgery (2007), and honorary president of the Colombian Society of Neurosurgery (2013).

Dr. Zuccaro has been invited as visiting professor at multiple neurosurgical departments around the world given her exceptional attributes as a teacher and a mentor. She continues to be a very active organizer of local, national, and international courses in neurosurgery, training medical students, residents, and colleagues alike (Fig. 5).

Fig. 6 Dr. Zuccaro with the staff of Hospital Garrahan

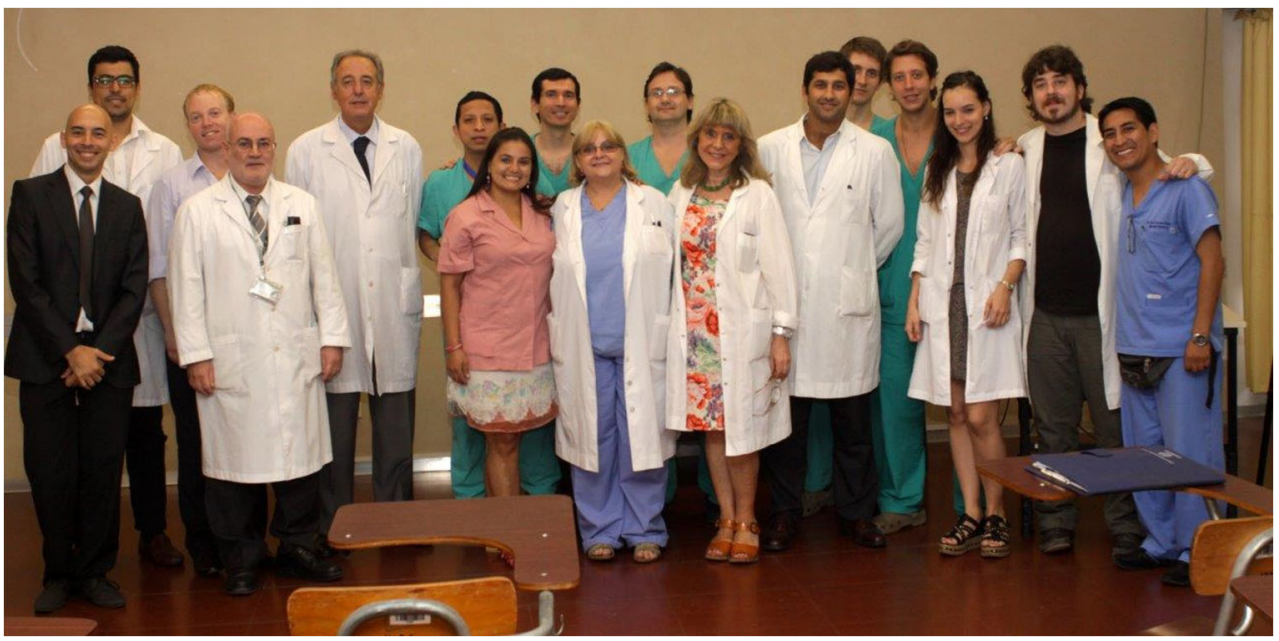

honorary member of the Colombian Society of 
Fig. 7 Dr. Zuccaro receiving the Poncho as the new president of the ISPN from her predecessor Dr. Chandrashekhar Deopujari, 2015

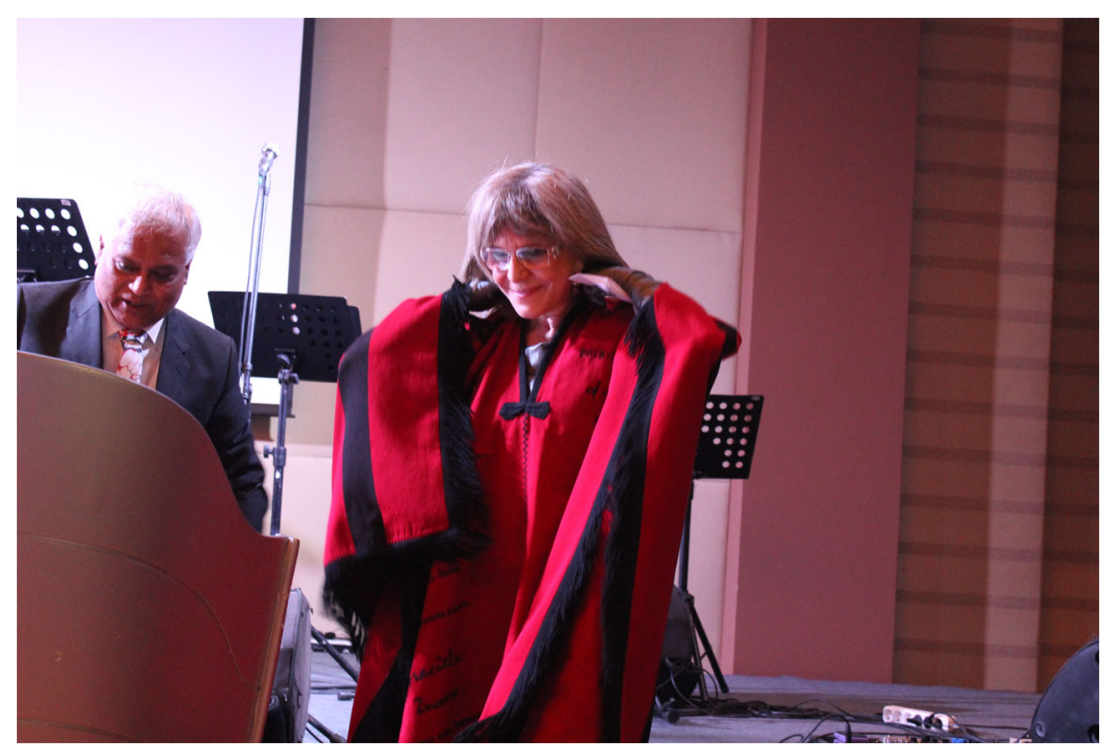

\section{Awards}

Dr. Zuccaro received 16 national and international awards. Just to name a few: In 1998, for her trajectory as a prominent neurosurgeon, she was awarded by the Argentinian Society of Neurosurgery; in 2013, she was honored with the Premio Konex in Sciences and Technology, a significant award granted each decade, honoring the best individuals in a surgical subspecialty in Argentina.

\section{ISPN}

The presidents of the International Society of Pediatric Neurosurgery (ISPN) are drawn from all continents of the globe, and the privilege of becoming a president is given to a member of our society who has made an outstanding contribution to pediatric neurosurgery and to the ISPN.

Dr. Zuccaro has been a member of the ISPN since 1993 with a busy and exemplary service. At the ISPN, she served as

Fig. 8 Gala Dinner, Izmir 2015. From left to right: Dr. and Mrs. Chandrashekhar Deopujari from India, Presiding President ISPN (2014-2015); Dr. Alejandro Olenchuk and Dr. Graciela Zuccaro from Argentina, President Elect ISPN (20152016); Dr. and Mrs. Saffet Mutluer from Turkey, president of the 43rd Annual Meeting of ISPN in Izmir

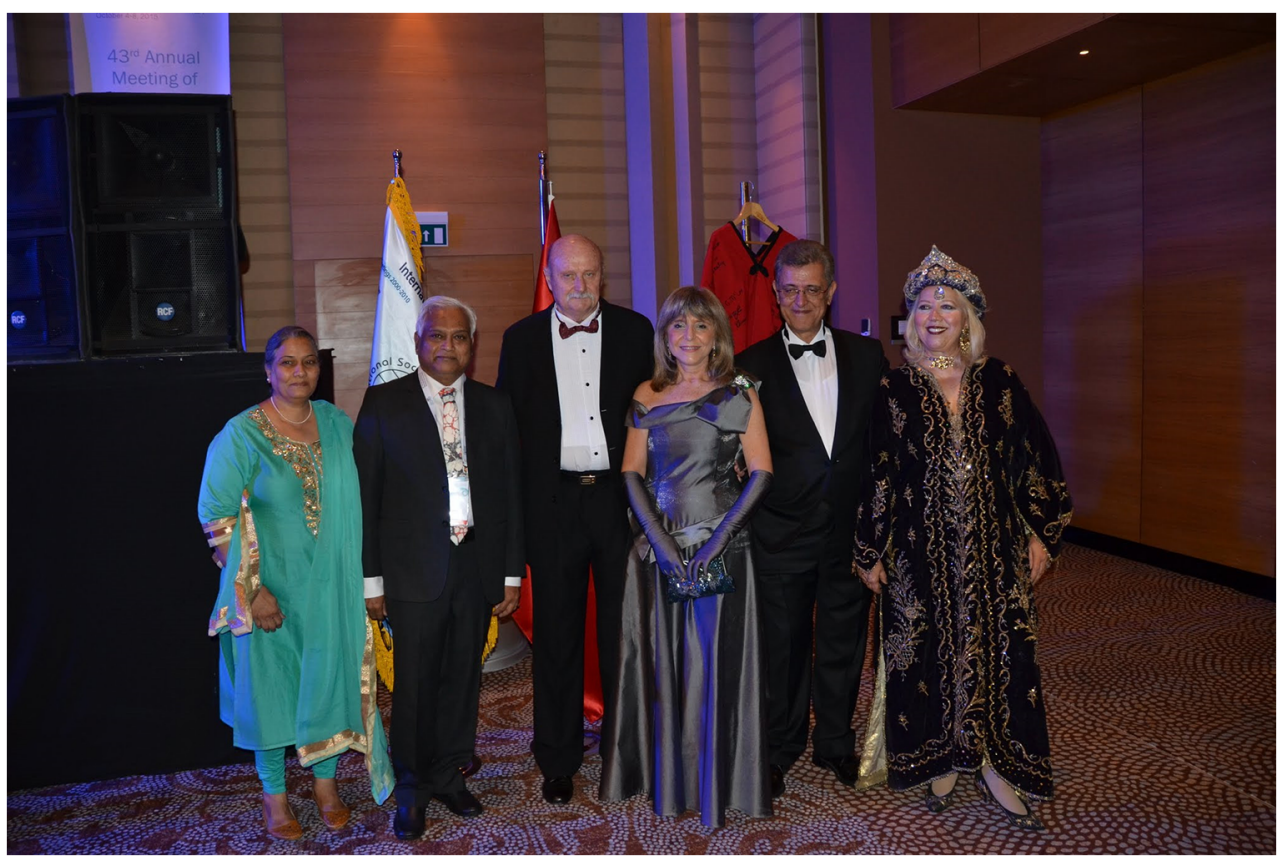




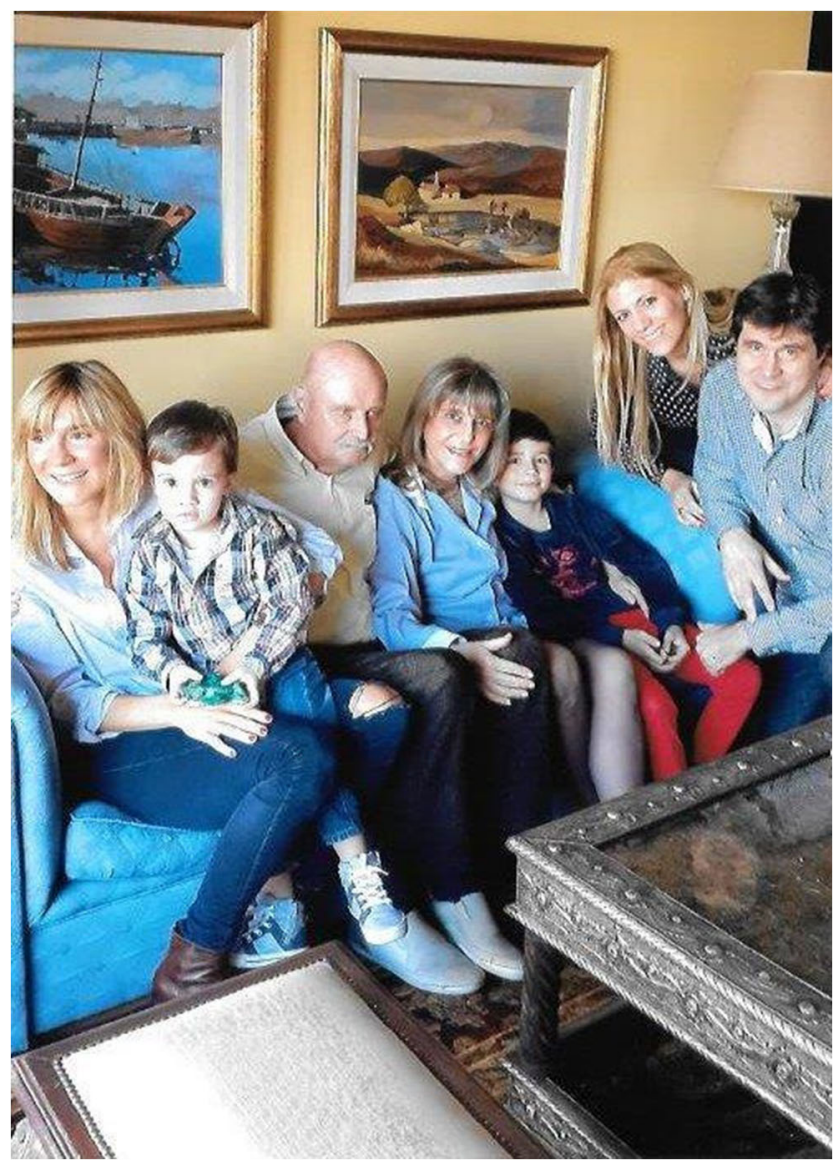

Fig. 9 Dr. Zuccaro with her husband Dr. Alejandro Olenchuk, her daughter Maria Clara, her son Rodolfo, her daughter in law Andrea, and her grandchildren Martin and Maximo
Chair of Ways and Means (2007-2009) and as secretary (2009-2012) before being elected as president in 2015 (Figs. 6, 7 and 8).

Dr. Zuccaro's successful career has been exceptional in many ways with her active participation in crucial times in the history of pediatric neurosurgery. Her leadership and vision, on moving forward the Latin-American neurosurgery, her contributions as a liaison between different neurosurgical societies and cultures, her pivotal role opening a doorway to many female neurosurgeons, and her impeccable balance on all the aspects of her life, definitely define her as the First Lady of the ISPN.

However, Graciela's most important role has been outside the operating room, as the wife of Alejandro, her partner and supporter for more than 45 years, her role of mother of Rodolfo and Maria Clara and the grandmother of Martin and of Maximo; without any doubt, she has been always the First Lady at home (Fig. 9).

Acknowledgements The author wants to thank Dr. Zuccaro for her insights on the biographic information, editing, and pictures.

\section{Compliance with ethical standards}

Conflict of interest The corresponding author reports no conflict of interest.

\section{References}

1. www.ISPNneurosurgery.org

2. www.flancpediatria.org 